\title{
Role of genetic variability in Mendelian and multifactorial diseases
}

\author{
Julián Ramírez-Bello*
}

Secretaría de Salud, Hospital Juárez de México, Research Unit, Mexico City, Mexico

\begin{abstract}
\end{abstract}
The first draft of the human genome sequencing published in 2001 reported a large number of single nucleotide polymorphisms (SNPS). Given that these polymorphisms could practically represent all the variability involved in the susceptibility, protection, severity, among other aspects, of various common diseases, as well as in their response to medications, it was thought they might be "the biomarkers of choice" in personalized genomic medicine. With the new information obtained from the sequencing of a larger number of genomes, we have understood that SNPs are only an important part of the genetic markers involved in these traits. In addition to SNPS, other variants have been identified, such as insertions/deletions (INDELs)-and copy number variants (CNVs), which - in addition to classic variable number tandem repeats (VNTRs) and short tandem repeats (STRs) - originate or contribute to the development of diseases. The use of these markers has served to identify regions of the genome involved in Mendelian diseases (one gene-one disease) or genes directly associated with multifactorial diseases. This review has the purpose to describe the role of STRs, VNTRs, SNPs, CNVs and INDELs in linkage and association studies and their role in Mendelian and multifactorial diseases.

KEY WORDS: Genetic variability. Polymorphism. Mutation. Multifactorial disease. Mendelian disease.

\section{Introduction}

In 1950, human genome mutations were thought to be extremely rare events. A couple of decades later, it was identified that RNA could be retro-transcribed into DNA. That information was to change our way of thinking: our genome was not stable but dynamic. In the following decades, several researchers identified a genome with great variability. The discovery of various mutations (DNA alterations with a frequency $<1 \%$ in the general population) or polymorphisms (common genetic variants with a frequency $\geq 1 \%$ in the general population), such as variable number tandem repeats (VNTRs), short tandem repeats (STRs), single nucleotide polymorphisms (SNPs), insertions/ deletions (INDELs) and copy number variants (CNVs) has served for identifying regions (or linked genes)) or genes associated with various diseases (Table 1

\section{Genetic variants used in linkage and association studies}

VNTRs and STRs have been used in linkage studies to detect regions involved with Mendelian (or monogenic) diseases, such as Duchenne or Becker muscular dystrophy, cystic fibrosis, sickle cell anemia, etc., which due to their low prevalence are quite rare in populations. These diseases have the characteristic that $a$ single altered gene results in a phenotype (Fig. 1 ), given that the mutation has great biological effect; however, there are always exceptions and, in some cases, even if a mutation occurs, it will not lead to the disease
Correspondence:

*Julián Ramírez-Bello

E-mail: dr.julian.ramirez.hjm @gmail.com
Date of reception: 29-01-2018

Date of acceptance: 06-12-2018

DOI: 10.24875/GMM.M20000333

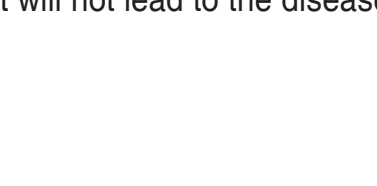

Gac Med Mex. 2019;155:463-470

Contents available at PubMed

www.gacetamedicademexico.com

0016-3813/@ 2018 Academia Nacional de Medicina de México, A.C.. Published by Permanyer. This is an open access article under the CC BY-NC-ND license (http://creativecommons.org/licenses/by-nc-nd/4.0/). 
Table 1. Characteristics of Mendelian and multifactorial diseases (for the latter, only traits of unrelated case-control studies-are mentioned)

\begin{tabular}{|c|c|}
\hline Traits & Mendelian disease \\
\hline Objective & $\begin{array}{l}\text { Identification of the main gene or genes linked } \\
\text { in the families }\end{array}$ \\
\hline Genetic alteration & Mutation \\
\hline Inheritance Model & $\begin{array}{l}\text { Well defined } \\
\text { Autosomal recessive, autosomal dominant, } \\
\text { X-linked, uniparental dysomia, etc. }\end{array}$ \\
\hline Effect of the alteration & $\begin{array}{l}\text { High } \\
\text { Generally, all individuals who have the mutation } \\
\text { in a single gene also have the disease (except } \\
\text { for incomplete penetrance) }\end{array}$ \\
\hline Frequency of the alteration & $\begin{array}{l}\text { Rare } \\
\text { Lower than } 1 \% \text { in a population }\end{array}$ \\
\hline Variants used in these studies & VNTRs, STRs, SNPs \\
\hline Effect of the environment & Practically none \\
\hline Clinical presentation & $\begin{array}{l}\text { They occur at the earliest stage of life or during } \\
\text { childhood }\end{array}$ \\
\hline
\end{tabular}

\section{Multifactorial disease}

Identification of the gene/genes of small effect size associated with a population base

Polymorphism

Undefined

Low

In individuals who have all associated variants they do no trigger the disease, but cause susceptibility to diseases Low-common With a frequency of at least $1 \%$ in the general population VNTRs, STRs, SNPs, CNVs, INDELs

Strongly influenced

They frequently occur more towards the stage of young adulthood or adulthood. Others, such as obesity and type 2 diabetes, currently also occur in children

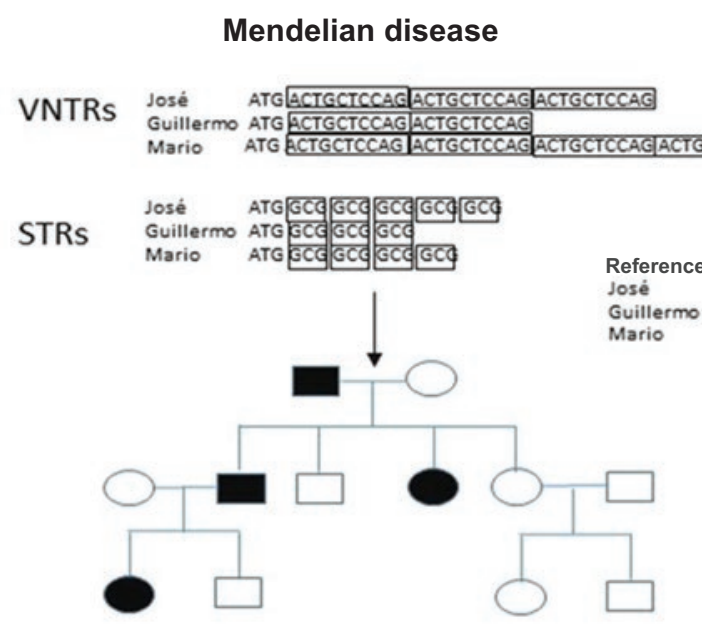

Families with multiple affected members

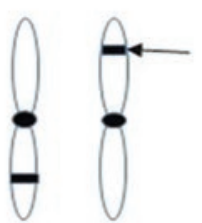

Chromosome 1

Chromosome 17
Regions linked to the disease

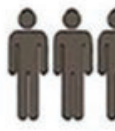
Multiple genes associated with the disease

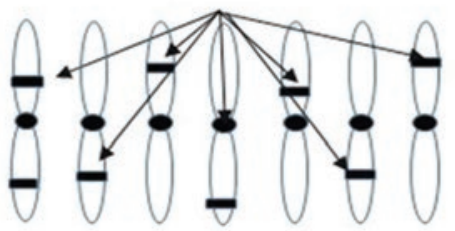

Chromosome 1

Chromosome 6

Chromosome 10 Chromosome 14

Chromosome 17 Chromosome 20 Chromosome 22 
but to incomplete penetrance, i.e., less than $100 \%$ of individuals have the expected phenotype according to their genotype (Table 1 and Figure 1).

Linkage (parametric) refers to a co-segregation of these markers with a disease or phenotype in families with multiple affected members; it is measured in a base 10 logarithm (LOD score) and it must show at least a LOD score of 3 , which means that the genetic marker shows a 1000-fold linkage with the trait of interest. Thus, a linkage positive signal (LOD score $\geq 3$ ) serves to identify chromosomal regions (although not necessarily the gene) involved in Mendelian pathologies (Fig. 1). ${ }^{8-10}$ Since this strategy does not detect the linked gene, but rather a chromosomal region, the next step is to detect the mutation in a nearby gene involved with the disease by other methodologies (Fig. 1).

On the other hand, in association studies, where the co-occurrence of a genetic marker with a disease or phenotype of interest is observed, ${ }^{8,9}$ VNTRs, STRs, SNPs, CNVs and INDELs are used with the purpose to detect genes associated with the trait of interest (Fig. 1). Given their abundance in the genome and relative ease to assess them with automated methods, SNPs are routinely used in this type of analysis. ${ }^{6,7}$ Their use in case-control investigations is highly convenient (this article only refers to case-control studies), since a much finer genetic mapping can be carried out versus VNTRs or STRs, which are scarce if compared to SNPs. Some SNPs can be assessed using studies of candidate genes (genes that encode or not proteins and that due to their biological effect participate in the pathogenesis of a disease), or thousands of them can be examined by means of genome-wide association studies (GWAS), which detect dozens of loci related to these traits (in these studies, no hypotheses are established because they do not target any particular gene).

It is important noting that, in order to obtain reliable results in GWAS, they must include hundreds or thousands of samples of cases and controls and be replicated in at least a second study group, corrections should be made and the Bonferroni test should be included (if one million SNPs are evaluated, then $p$-values $=0.05 / 10^{-6}$ should be established, i.e., $\left.5 \times 10^{-8}\right)$, as well as a correction for ancestry (through informative markers of ancestry), etc.; some functional test of associated variants is also suggested. ${ }^{11}$ Linkage and association studies have several differences (Table 1).

\section{Mutation or polymorphism}

In Mendelian or multifactorial diseases, mutations and polymorphisms, although representing a change in the DNA sequence, are defined differently due to their allelic frequency and biological effect in an individual (Fig. 2). In Mendelian diseases, mutations are mentioned, while in multifactorial diseases, polymorphisms are referred to. In the former, a single mutation in a gene (with a frequency $<1 \%$, which doesonot occur in the general population) is enough for cystic fibrosis, Duchenne or Becker muscular dystrophy, among others, to occur (except in case of incomplete penetrance), and practically they are not influenced by the environment (Fig. 2). In these diseases, mutations follow a well-defined heritability pattern andinclude autosomal recessive, autosomal dominant, X-linked, etc. inheritance. ${ }^{12}$

In turn, multifactorial diseases are influenced by tens or hundreds of (polygenic) susceptibility genes, and each loci contributes with a small effect size (Fig. 2). Additionally, the alleles of the associated variants have frequencies that range from low to normal (Fig. 2), without a well-defined inheritance pattern (owing to this trait, they are also defined as complex diseases), with environmental risk factors being involved in their development; i.e. even with all risk alleles, an individual will not develop the disease unless there is an environmental risk factor that triggers its devetopment (Table 1 and Figure 2);,6,7 for example, in some autoimmune diseases such as rheumatoid arthritis (RA) and systemic lupus erythematosus (SLE), $\frac{\text { more }}{\text { mot }}$ than 100 genes associated with susceptibility have been identified; however, these are not sufficient to trigger the disease..$^{13,14}$

\section{VNTRs in Mendelian and multifactorial diseases}

VNTRs, also known as mini-satellites, comprise tandem repeats of non-coding sequences of 10 to 100 nucleotides in length (Fig. 1). Approximately 1500 VNTRs have been calculated to exist in the human-genome. ${ }^{1,4,10}$ Their use as markers for linkage studies occurred in the early 1980s, when they were used to map chromosomal regions linked to various Meñdelian diseases (Fig. 1). VNTRs were useful for identtifying "signals" close to the main causative genes of these diseases; subsequent studies identified those genes. ${ }^{8,10}$ 


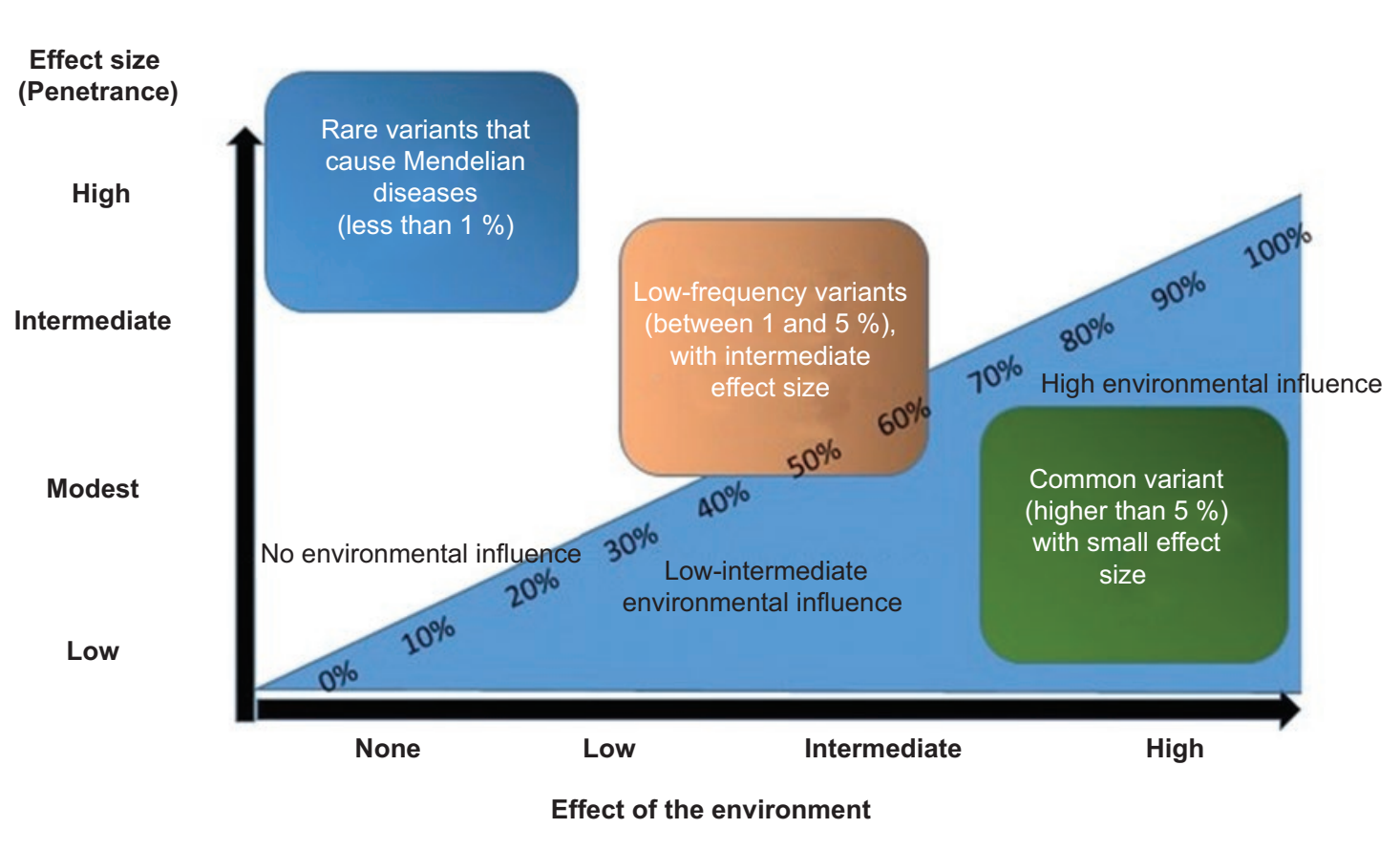

Figure 2. Image depicting the effect of the environment; and of mutations-polymorphisms in the genesis of Mendelian and multifactorial diseases. The environment has little or no effect on the genesis of most Mendelian diseases (caused by mutations); in contrast, it can influence up to nearly $100 \%$ on multifactorial diseases (multiple genes and with a small effect size), while gene variants can have little or much relevance ith the development of these diseases.

On the other hand, the use of VNTRs in linkage analyses for complex diseases were not as successful as expected, since these diseases are influenced by several genes with a small effect size (there is not a main gene)..$^{8}$ In addition, VNTRs have been used in genetic association studies, although currently they have been practically forgotten mainly due to their low number and because the vast majority are located at chromosomal terminal regions. However, not studying them potentially implies "losing" (lossing heritability) some loci involved in this type of diseases. A 28-bp VNTRs located in the HRAS oncogene has been proposed to cause susceptibility to several types of cancer through the following mechanisms:

- Linkage disequilibrium, i.e., some alleles of this VNTRs are in linkage disequilibrium with the true variant associated in those tumors.

- Disruption of rel-NF-kB transcription factors gene expression, since it is located at a binding site for that family of transcription factors and could be a direct cause of the association. ${ }^{1}$

On the other hand, a VNTRs with four repeated $27 \mathrm{bp}$ was recently identified, which is located in exon 4 of the endothelial nitric oxide synthase (eNOS3) gene that confers susceptibility to coronary artery disease. Correlation studies showed that this VNTRs is associated with high serum triglyceride levels (versus that of five $27 \mathrm{bp}$ repeats), while the in silico analysis showed that this repeat can affect alternative splicing. ${ }^{15}$

Other VNTRs located in myoglobin, interleukin- receptor antagonist, DNase 1, and interleukin-4 geñes, among others, have been observed to be associated with RA, SLE and osteoarthritis (Table 2). ${ }^{16-18}$

\section{STRs in Mendelian and multifactorial diseases}

STRs (also known as microsatellites) are tandem-repeats that range from 2 to $10 \mathrm{bp}$, although somecauthors define them as 2 bp-repeats (Fig. 1). Due to their wide distribution in the human genome, they reach up to $3 \%$ of total nucleotides, accounting for nearly $6 \%$ of coding regions (where the 5' untranslated, coding sequence and 3' UTR regions are included). ${ }^{3}$ Recently, a first catalog of human STRs has been reported at the level of wide population-based genome studies: nearly 700,000 STRs have been identified in 1009 individuals in phase 1 of the 1000 Genomes Project, an outstanding finding because it will contribute to identify part of the "missing heritability" in multifactorial diseases. 3

STRs are found in different parts of the structure of protein-coding genes and can have an effect on gene expression, RNA stability and creation or destruction 
Table 2. Genetic variants involved in Mendelian and multifactorial diseases

\begin{tabular}{|c|c|}
\hline Variant & Mendelian disease \\
\hline \multirow[t]{2}{*}{ VNTRs } & Hypertension \\
\hline & Linked chromosomal regions: 2p22.1, 5q33 \\
\hline \multirow[t]{2}{*}{ STRs } & $\begin{array}{l}\text { Different STRs have been linked in more than } \\
40 \text { Mendelian diseases; these diseases include } \\
\text { spinocerebellar ataxia, Huntington's disease, spinobulbar } \\
\text { muscular atrophy, myotonic dystrophy }\end{array}$ \\
\hline & Hungtintin gene, ATXN3, DM1 \\
\hline SNPS & - \\
\hline \multirow[t]{2}{*}{ CNVs } & $\begin{array}{l}\text { Autosomal dominant microtia, neurodevelopmental } \\
\text { diseases such as autism and epilepsy, congenital heart } \\
\text { defects, etc. }\end{array}$ \\
\hline & Identified chromosomal regions: 4p16 \\
\hline INDELS & - \\
\hline
\end{tabular}

Multifiactorial disease

References

Various types of cancer, rheumatoid arthritis, SLE, osteoarthritis

Genes: HRAS, IL1, IL4, DNase 1

Various types of cancer, autoimmune diseases

of an open reading frame, etc. ${ }^{3}$ They have high hypermutability, i.e., the repeats tend to generate more copies due to recombination or replication errors. These variants have been used as genetic biomarkers in linkage studies with more success than VNTRs due to their wider distribution. ${ }^{8}$ For example, some studies in RA (a complex and multifactorial disease) showed that several STRs localized in chromosome 6p21 are important for this pathology; simultaneously, other linked regions in this autoimmune disease were identified with these markers. ${ }^{19,20}$

On the other hand, several STRs have been linked to more than 40 Mendelian diseases, including spinocerebellar ataxia, Huntington's disease, spinobulbar muscular atrophy, among others, which originate from a dramatic expansion of trinucleotides and behave as dominant gain-of-function mutations. ${ }^{3,21}$

The CAG STRs (a codon involved in glutamine encoding), located in the coding sequence of the huntingtin gene, has been identified as the responsible for Huntington's disease (Table 2); in 1993, less than 35 repeats were identified in healthy individuals, while those affected had 37 or more glutamine repeats, which leads to a change in the structure and function of the protein. ${ }^{22,23}$ Another example is spinocerebellar
Genes: KCNQ10T1, PTPN11, ECRG2, TCR

Various types of autoimmune, metabolic, etc., diseases

Genes: PTPN22, TNF, FCRL3, microRNA, FTO, LEPR etc.

Various cancers, autoimmune, mental diseases, etc

Genes: FCGR3B, C4, CCL3L1, NBPF, UGT2B17

Multiple sclerosis, SLE, obesity and body mass index

Genes: BAFF, LEPR, UCP2

SLE = sytemile nucleotide polymorphisms, CNVs = copy number variants, INDELs = insertions/d PTPN11 = protein tyrosine phosphatase non-receptor type 11, ECRG2 = esophageal cancer-related gene 2, TCR $=$ T-cell receptor, PTPN22 = protein tyrosine phosphatase 作 ataxia type 3 (Table 2), in which an expansion of the CAG trinucleotide in the coding sequence of the ATXN3 gene (which encodes the ataxin 3 protein) is also associated with abnormal folding of the protein and with an accumulation in certain regions of the brain. ${ }^{24}$ On the other hand, the CTG repeat, located in the gene that encodes protein kinase MD1 has been implicated in myotonic dystrophy type 1 and the GGGGCC repeat of the C9ORF72 hypothetical gene is involved in the onset of frontotemporal dementia.

Regarding the role of STRs in multifactorial diseases, several of them have been associated with susceptibility; for example, the STRs located in the KCNQ1OT1 gene (long non-coding RNA gene involved in the silencing of a cluster of genes incis) causes a decrease in the risk for the development of hepatocellular carcinoma. ${ }^{26}$ Other STRs located in genes such as PTPN11, ECRG2 and TCR have been associated with the development of various cancers and autoimmune diseases (Table 2). ${ }^{27-30}$

\section{SNPs and multifactorial diseases}

SNPs are single-nucleotide variants, generally bialIelic, and represent the most abundant polymorphisms 
of human genome (found every 200 to $500 \mathrm{bp}$ ). Recent data from 1000 Genomes Project indicate that there are nearly 11 million of them and each individual has an average of three million. ${ }^{5,31,32}$ Given their wide distribution, SNPs are found in regions where there are genes present or not. In the former, they are located in any part of its structure and include promoters, exons and introns, while SNPs located in non-coding RNA genes can be found in the promoters or in the non-coding sequence. ${ }^{7}$ From a functional point of view, SNPs located in protein coding and non-coding genes affect various processes that are mentioned in detail in the article "Functional implications of single nucleotide polymorphisms (SNPs) in protein-coding and non-coding RNA genes in multifactorial diseases". ${ }^{7}$

Since their discovery, SNPs have been used in association studies. ${ }^{7,33}$ Associations between these variants and multifactorial traits are measured according to their statistical significance, which is generally $p \leq 0.05$ for candidate gene studies or $p \leq 5 \times 10^{-8}$ for GWAS. ${ }^{11,34}$ However, it is important taking into account certain deficiencies in candidate gene investigations, including population stratification, low sample size, low statistical power, etc., ${ }^{9,11,33}$ which do not represent a problem in GWAS, whose analysis includes evaluating various ancestry markers, a large sample size (hundreds or thousands of case-controls), replications of the findings in other samples, as well as elimination of other biases that may confound associations. ${ }^{11}$ Through both strategies, multiple genes associated with multifactorial diseases have been recognized; $6,7,11,33$ for example, a candidate gene study identified that SNPs in pre-miRNAs 146a and 499 confers susceptibility to SLE, ${ }^{35}$ while the non-synonymous C1858T SNPs -which leads to a change of arginine for tryptophan at position 620 of the PTPN22 mRNA- confers susceptibility to $\mathrm{RA}^{36}$ and Graves' disease, ${ }^{37}$ since it affects the structure and function of the protein, as well as various immune processes. ${ }^{36}$ The $C$ allele of FCRL3 SNPs-169T/C -which codes for $F c$ receptor-like protein 3-modifies binding affinity for NF-kB transcription factor and is correlated with higher levels of mRNA of this receptor involved in B-cell activation, which causes susceptibility to SLE and RA (Table 2). ${ }^{6,7}$

On the other hand, a recent analysis of 225 SNPs recorded in a database of polymorphisms previously associated with obesity, identified that 15 variants of the FTO gene are associated with body mass index, and thus it replicated previous findings and confirmed that FTO represents the main risk locus for this trait ${ }^{38}$ Although these variants are found in intron 1 of this gene, functional studies show that some SNPs can form long-range connections to regulate the expression of the IRX3 gene, which has been implicated in some obesity-related events through FTO. ${ }^{38}$ Another study has shown the role of various SNPs located in the leptin receptor gene (LEPR) and their relationship with susceptibility to obesity. ${ }^{39}$ There are other examples about the role of SNPs and their relationship with multifactorial diseases. ${ }^{6,7}$

\section{CNVs in Mendelian and multifactorial diseases}

CNVs (a type of structural variation) encompass segments of DNA with a length equal to or larger than $1 \mathrm{~kb}$, which occur in a variable number of copies between individuals and comprise deletions, duplications and insertions (Fig. 1). ${ }^{40} \mathrm{CNVs}$ have been suggested to influence on up to $1 \%$ of variability between two individuals, while SNPs account for about $0.1 \%{ }^{40}$ In addition, CNVs can cause Mendelian diseases and susceptibility to multifactorial diseases. ${ }^{40-42}$ Unfortunately, the amount of CNVs identified in the human being is not defined, since it depends on the nature of the arrangement used to assess them. Currently, in the CNVs database, there are 29,133 included, with $41 \%$ overlapping with known genes, which means that an important part of them can cause Mendelian or multifactorial diseases. ${ }^{43}$ From the biological-pathological effect point of view, CNVs are the most important variants (due to their size) related to susceptibility for various human diseases (when compared to VNTRs, STRs and SNPS). They have been reported to cause Mendelian diseases in neonatal or early stages of childhood, including neurodevelopmental diseases such as autism or eppilepsy and congenital heart defects, among others (Table 2). ${ }^{43}$

Regarding multifactorial diseases, an 8-kb CAV/s localized in the NEGR1 gene has been recently shown to be associated with protection against obesity, and a functional study indicated that the NKX6 transeription factor binds to this region and represses its transcription, and thus the deletion of this CNVs prevents the binding of this transcription factor. Additional tests are still required to better understand its role in obesity. ${ }^{39}$

On the other hand, several CNVs located in FCGR3B, C4, CCL3L1, and DEBF have been associated 
with the development of glomerulonephritis in patients with SLE, HIV/AIDS and psoriasis, respectively (Table 2). ${ }^{2,41-43}$ It is important mentioning that the data on genetic association of CNVs located in FCGR3B, CCL3L1, DEBF and C4 should be taken with great caution since these associations should be identified with SNPs microarray studies; however, so far there is no evidence of association of these variants using these molecular tools.

\section{INDELs and multifactorial diseases}

Recently, small INDELs (Fig. 1) have been reported in the human genome, which comprise a length of 1 to $10,000 \mathrm{bp} .^{44}$ A study on chromosome 22 showed that out of $100 \%$ of variants, $13 \%$ corresponded to INDELs. ${ }^{44}$ Other research carried out on 330 genes from different individuals reported 2,393 small INDELs from 1 to $543 \mathrm{bp}$ in length. ${ }^{44}$ On the other hand, 3.4 million of small INDELs were identified, out of which 1.96 million were non-redundant, while 819,363 were located in human genes, out of which 2,123 were found in exons. The final number of INDELs identified in the genome is also not established, since it depends on the last-generation tool used and the amount of INDELs each person has; for example, the Watson genome contains 222,718, while the Venter genome possesses $823,396 . .^{44}$

Given their recent identification, INDELs have not been assessed in linkage analyses, but in association analyses they have. From the functional point of view, and given that small INDELs (especially those that cover some tenths of bp) can be found in genes and affect promoters, exons (5' UTR, coding sequence, and 3 ' UTR) and introns, and possibly influence on the development of multifactorial diseases because they are also capable of altering aspects of mRNAs or proteins, for example, 184 INDELs out of 2,123 are close to the binding sites between exons and introns, thus affecting splicing and mRNA-proteins that are useful for cells; the remaining 1939 are located in the coding sequence and cause alterations in the reading frameshift or in premature termination of the protein. ${ }^{45,46}$

Regarding the role of these variants and their genetic association with some diseases, the GCTGT-> A INDELs (the A allele confers risk), located in the 3 'UTR region of the TNFSF13B gene (which codes for the B-cell activating factor cytokine) has been reported to confer risk for the development multiple sclerosis and SLE in patients from various European countries (Table 2). ${ }^{47}$ It is important mentioning that variant $A$ of the GCTGT-> A INDELs generates a short mRNA that escapes the inhibition of a microRNA (a negative regulator of the expression of various mRNAs at the post-transcriptional level), which leads to increased production of the soluble B-cell activating factor cytokine in these patients, thus causing susceptibility to the development of said diseases. ${ }^{47}$

On the other hand, the CTTTA INDELs localized at the 3' UTR region of the LEPR gene is associated with body weight increase, ${ }^{48}$ while the 45 -bp INDELs located in the 3' UTR region of the UCP2 gene (which codes for an uncoupling protein that acts as a mitochondrial transporter and homeostasis and thermogenesis energy regulator) has been associated with body mass index and body weight alterations after food consumption. ${ }^{4}$

Another study assessed a group of INDELs in vavarious genes of patients with colorectal cancer; these variants in the ACE, UCP2, TYMS, IL4, NFKB1, CASP8, TP53, HLAG, UGT1A1 and SGSM3 genes were found to be associated with susceptibility and some clinical traits (Table 2). ${ }^{49}$ Other small INDELs located in the PPP3R1, PARP1, pre-miR3131, COLAA2 and $H L A-G$ genes have shown an association with susceptibility for coronary artery disease, melanoma, hepatocellular carcinoma, osteoporosis and SLE, respectively. ${ }^{50-54}$

\section{Conclusions}

Genetic markers such as VNTRs, STRs, SNPS, CNVs and INDELs have been useful for identifying genes related to Mendelian and multifactorial diseases. Since their appearance, VNTRs and STRs were used in linkage studies to identify regions involved with rare diseases; however, in common diseases they were not successful. With SNPs subsequent identification, they became the genetic markers of choice for genetic association studies. Currently, with the analysis of INDELs and CNVs through various tools of low, medium and high density, we have begun to understand their role in the genesis of Mendelian diseases and in susceptibility to multifactorial diseases. In the not too distant future, knowing the genomic variability involved in both types of diseases will result in the development of individualized, preventive and predictive medicine.

\section{References}

1. Ramel C. Mini-and microsatellites. Environ Health Perspect. 105:781-789.

2. Haraksingh RR, Snyder MP. Impacts of variation in the human genome on gene regulation. J Mol Biol. 2013;425:3970-3977. 
3. Press MO, Carlson KD, Queitsch C. The overdue promise of short tandem repeat variation for heritability. Trends Genet. 2014;30:504-512.

4. Richard GF, Kerrest A, Dujon B. Comparative genomics and molecula dynamics of DNA repeats in eukaryotes. Microbiol Mol Biol Rev. 2008; 72:686-727.

5. Abecasis GR, Altshuler D, Auton A, Brooks LD, Durbin RM, Gibbs RA et al. A map of human genome variation from population-scale sequencing. Nature. 2010;467:1061-1073.

6. Ramírez-Bello J, Vargas-Alarcón G, Tovilla-Zárate C, Fragoso JM. Single nucleotide polymorphisms (SNPs): functional implications of regulatory-SNPs (rSNPs) and structural RNA (srSNPs) in complex diseases. Gac Med Mex. 2013;149:220-228.

7. Ramírez-Bello J, Jiménez-Morales M. Functional implications of single nucleotide polymorphisms (SNPs) in protein-coding and non-coding RNA genes in multifactorial diseases. Gac Med Mex. 2017:153:238-250.

8. Ramírez-Bello J, Pérez-Méndez O, Ramírez-Fuentes S, Carrillo-Sánchez S, Vargas-Alarcón G, Fragoso JM. Genetics and genomic studies in the hypertension: an actualization of the genomic studies. Arch Cardiol Mex. 2011:81:240-250.

9. Baron M. The search for complex disease genes: fault by linkage or fault by association? Mol Psychiatry. 2001;6:143-149.

10. Nakamura $Y$. DNA variations in human and medical genetics: 25 years of my experience. J Hum Genet. 2009;54:1-8.

11. Pearson TA, Manolio TA. How to interpret a genome-wide association study. JAMA. 2008;299:1335-1344

12. Vink JM, Boomsma DI. Gene finding strategies. Biol Psychol. 2002; 61:53-71

13. Rodríguez-Elías AK, Maldonado-Murillo K, López-Mendoza LF, Ramírez Bello J. Genetics and genomics in rheumatoid arthritis (RA): an update. Gac Med Mex. 2016;152:218-227.

14. Teruel M, Alarcón-Riquelme ME. The genetic basis of systemic lupus erythematosus: What are the risk factors and what have we learned. J Autoimmun. 2016;74:161-175.

15. Teralı K, Ergören MÇ. The contribution of NOS3 variants to coronary artery disease: a combined genetic epidemiology and computational biochemistry perspective. Int J Biol Macromol. 2018:123:494-499.

16. Carreira PE, González-Crespo MR, Ciruelo E, Pablos JL, Santiago B, Gómez-Camara A, et al. Polymorphism of the interleukin-1 receptor antagonist gene: a factor in susceptibility to rheumatoid arthritis in a Spanish population. Arthritis Rheum 2005; 52: 3015-3019.

17. AlFadhli S, Ghanem AA. Influence of human DN1 VNTRs polymorphism on DNASE1 expression in systemic lupus erythematosus and rheumatoid arthritis. Immunol Invest. 2014:43:411-423.

18. Yigit S, Inanir A, Tekcan A, Tural E, Ozturk GT, Kismali G, et al. Significant association of interleukin-4 gene intron 3 VNTRs polymorphism with susceptibility to knee osteoarthritis. Gene. 2014:537:6-9.

19. Viatte S, Plant D, Raychaudhuri S. Genetics and epigenetics of rheumatoid arthritis. Nat Rev Rheumatol. 2013;9:141-153.

20. Cornélis F, Fauré S, Martinez M, Prud'homme JF, Fritz P, Dib C, et al. New susceptibility locus for rheumatoid arthritis suggested by a genome-wide linkage study. Proc Natl Acad Sci U S A. 1998; 95:10746-10750

21. Willems T, Gymrek M, Highnam G, Mittelman D, Erlich Y, 1000 Genomes Project Consortium. The landscape of human STRs variation. Genome Res. 2014;24:1894-1904.

22. Aronin N, Kim M, Laforet G, DiFiglia M. Are there multiple pathways in the pathogenesis of Huntington's disease? Philos Trans R Soc Lond B Biol Sci. 1999;354:995-1003.

23. Roos CA, Tabrizi SJ. Huntington's disease: from molecular pathogenesis to clinical treatment. Lancet Neurol. 2011;10:83-98.

24. Paulson H. Machado-Joseph disease/spinocerebellar ataxia type 3. Handb Clin Neurol. 2012;103:437-449.

25. Rohilla KJ, Gagnon KT. RNA biology of disease-associated microsatellite repeat expansions. Acta Neuropathol Commun. 2017;5:63.

26. Wang J, Huang $M$, Zhao $H$, Wang $C$, Zhao $X$, Jiang $X$, et al. A novel tetranucleotide repeat polymorphism within KCNQ1OT1 confers risk for hepatocellular carcinoma. DNA Cell Biol. 2013;32:628-634.

27. Zhao X, Hu S, Wang L, Zhang Q, Zhu X, Zhao H, et al. Functional short tandem repeat polymorphism of PTPN11 and susceptibility to hepatoceIlular carcinoma in Chinese populations. PLoS One. 2014:9:e106841.

28. Yue CM, Bi MX, Tan W, Deng DJ, Zhang XY, Guo LP, et al. Shor tandem repeat polymorphism in a novel esophageal cancer-related gene (ECRG2) implicates susceptibility to esophageal cancer in Chinese population. Int J Cancer. 2004;108:232-236.

29. Hsu LM, Huang YS, Yang SY, Chang FY, Lee SD. Polymorphism of T-cell receptor gamma short tandem repeats as a susceptibility risk factor of hepatocellular carcinoma. Anticancer Res. 2006;26:3787-3791.
30. Dziedzieiko V, Kurzawski M, Safranow K, Ossowski A, Piatek J, Parafiniuk $\mathrm{M}$, et al. CAG repeat polymorphism in the androgen receptorgene in women with rheumatoid arthritis. J Rheumatol 2012; 39: 10-17.

31. Manolio TA, Collins FS, Cox NJ, Goldstein DB, Hindorff LA, Hunteer DJ, et al. Finding the missing heritability of complex diseases. Nature. 2009;461:747-753

32. Mayeux R. Mapping the new frontier: complex genetic disorders. I Clin Invest. 2005:115:1404-1407.

33. Hanchard NA. Genetic susceptibility and single-nucleotide polymorphisms. Semin Fetal Neonatal Med. 2005;10:283-289.

34. Lewis CM, Knigth J. Introduction to genetic association studies. Cold Spring Harb Protoc. 2012;2012:297-306.

35. Alemán-Ávila I, Jiménez-Morales M, Beltrán-Ramírez O, Barbosa-Cobos̊ RE, Jiménez-Morales S, Sánchez-Muñoz F, et al. Functional polymorphișns in pre-miR-146a and pre-miR499 are associated with systemic lupus erythematosus but not with rheumatoid arthritis or Graves' disease in Mexican patients. Oncotarget. 2017;8:91876-91886.

36. Rincón JF, Cano DL, Morales SJ, Jiménez ML, Cobos RE, Belld JPR.The functional PTPN22 C1858T polymorphism confers risk for rheumatoid arthritis in patients from Central Mexico. Clin Rheumatol. 2016 ; 35:1457-1462.

37. López Cano DJ, Cadena-Sandoval D, Beltrán-Ramírez O, Barbosa-Cobos RE, Sánchez-Muñoz F, Amezcua-Guerra LM, et al. The PTPN22 $\mathrm{R} 263 \mathrm{Q}$ polymorphism confers protection against systemic lupus erythematosus and rheumatoid arthritis, while PTPN22 R620W confers susceptibility to Graves' disease in a Mexican population. Inflamm-Res. 2017;66:775-781.

38. Mao L, Fang Y, Campbell M, Southerland WM. Population differentiation in allele frequencies of obesity-associated SNPs. BMC Genomics. 2017;18:861.

39. Wheeler E, Huang N, Bochukova EG, Keogh JM, Lindsay S, Garg S, et al. Genome-wide SNPs and CNVs analysis identifies common and low-frequency variants associated with severe early-onset obesity. Nat Genet. 2013;45:513-517.

40. Chen L, Zhou W, Zhang L, Zhang F. Genome architecture and its role in human copy number variation. Genomics Inform. 2014;12:136-144.

41. Riggs ER, Ledbetter DH, Martin CL. Genomic variation: Lessons learned from whole-genome CNVs analysis. Curr Genet Med Rep. 2014;2:146150.

42. Choy KW, Setlur SR, Lee C, Lau TK. The impact of human copy number variation on a new era of genetic testing. BJOG. 2010;117:391-398.

43. Martin CL, Kirkpatrick BE, Ledbetter DH. Copy number variants, àneuploidies, and human disease. Clin Perinatol. 2015;42:227-242.

44. Mullaney JM, Mills RE, Pittard WS, Devine SE. Small insertions and deletions (INDELs) in human genomes. Hum Mol Genet. 2010;19:R131-R'136.

45. Bhangale TR, Stephens M, Nickerson DA. Automating resequencing-based detection of insertion-deletion polymorphisms. Nat Genet. 2006;38:1457-1462

46. Mills RE, Pittard WS, Mullaney JM, Farooq U, Creasy TH, Mahurkar AA, et al. Natural genetic variation caused by small insertions and deletions in the human genome. Genome Res. 2011:21:830-839.

47. Steri M, Orrù V, Idda ML, Pala M, Sidore C, Faà V, et al. Overexpression of the cytokine BAFF and autoimmunity risk. N Engl J Med. 2017 ; $376: 1615-1626$

48. Say YH. The association of insertions/deletions (INDELs) and variable number tandem repeats (VNTRs) with obesity and its related traits and complications. J Physiol Anthropol. 2017;36:25.

49. Marques D, Ferreira-Costa LR, Ferreira-Costa LL, Correa RDS Borges AMP, Ito FR, et al. Association of insertion-deletions polymorphisms with colorectal cancer risk and clinical features. World J Gastroefferol. 2017:23:6854-6867.

50. Maddhuri S, Bandaru S, Bhukya C, Cingeetham V, Malempati AR, Deepika MLN, et al. Association of CnB 5I/5D promoter gene polymorphism and serum calcineurin levels in early onset of coronary artery disease of south Indian cohort. Gene. 2017;632:1-6.

51. Choi J, Xu M, Makowski MM, Zhang T, Law MH, Kovacs MA, et al. A common intronic variant of PARP1 confers melanoma risk and mediates melanocyte growth via regulation of MITF. Nat Genet. 2017:49:1326-1335.

52. Wang C, Li L, Yin Z, Zhang Q, Zhao H, Tao R, et al. An indel polymorphism within pre-miR3131 confers risk for hepatocellular carcinoma. Carcinogenesis. 2017:38:168-176.

53. Jiang ZS, Hao ZH. An insertion/deletion polymorphism within the 3 -untranslated region of COL1A2 confers susceptibility to osteoporosis Mol Med Rep. 2016;14:4415-4421.

54. Hachiya Y, Kawasaki A, Oka S, Kondo Y, Ito S, Matsumoto I, et al. Association of HLA-G 3' untranslated region polymorphisms with systemic lupus erythematosus in a Japanese population: A case-control association study. PLoS One. 2016:11:e0158065. 